\begin{abstract}
One of the inflammatory responses of the eye to local application of platelet-activating factor (PAF) is oedema of the conjunctiva, caused by extravasation of plasma. Aim of the study was to investigate if fluorescein would leak from the blood into the tears together with plasma protein after application of PAF to the eye. Fluorescein was given intraperitoneally $30 \mathrm{~min}$ prior to application of $25 \mu 1$ of $0.1 \%$ solution of PAF. Thirty min after PAF the tear film was collected by washing the surface of the eye with $25 \mu 1$ of phosphate buffered saline (PBS). Fluorescein in eye washings and in plasma was measured by fluorophotometry and albumin by immunodiffusion. Both fluorescein and albumin appeared in a related fashion in tears, being absent in washings of placebo-treated control eyes. Extravasation of fluorescein can be used as a measure for plasma leakage in the conjunctiva with the advantage over the Evans Blue method that the former is a non-invasive method.
\end{abstract}

Key words: Platelet-activating factor (PAF), Fluorescein, Albumin, Guinea pig, Blood-tear barrier

\section{Permeability of blood-tear barrier to fluorescein and albumin after application of platelet-activating factor to the eye of the guinea pig}

\author{
J. L. van Delft ${ }^{1, C A}$, F. Meijer ${ }^{2}$, J. A. van Best ${ }^{1}$ and \\ N. J. van Haeringen ${ }^{2}$
}

${ }^{1}$ Department of Ophthalmology, Leiden University Medical Center, Albinusdreef 2, 2333 ZA Leiden; and ${ }^{2}$ The Netherlands Ophthalmic Research Institute, Amsterdam, The Netherlands

${ }^{\mathrm{CA}}$ Corresponding Author

Tel: $(+31) 715261776 / 2378$

Fax: $(+31) 715248222$

\section{Introduction}

The blood-tear barrier, causing the large concentration differences between tear and blood components, is formed by the acinar and ductal cells of the lacrimal gland and by the conjunctival and corneal epithelium at the surface of the eye.

Breakdown of the blood-tear barrier occurs in allergic conjunctivitis, where increased vascular permeability has been described as an important feature. ${ }^{1}$ Besides histamine and prostaglandins, platelet activating factor (PAF) takes part in the inflammatory process. ${ }^{2}$ On a molar basis PAF appeared to be $10^{3}$ to $10^{4}$ times more potent in inducing vascular permeability changes in skin compared with histamine. ${ }^{3}$ In guinea pigs topical application of PAF on the eye produces within $30 \mathrm{~min}$ a dose-dependent increase of the vascular permeability of the conjunctiva, as determined by measurement of the serum albumin concentration in lavage fluid of the surface of the eye. ${ }^{1}$

The aim of the present study is to investigate if application of PAF to the eye might also cause leakage of intraperitoneal injected fluorescein from blood into the tears together with serum albumin. Both fluorescein and albumin appeared significantly correlated in the eye washings after application of PAF

\section{Materials and Methods}

Eight female Hartley strain guinea pigs (weight range $350-450 \mathrm{~g}$ ) were intraperitoneally injected with $0.25 \mathrm{ml} / \mathrm{kg}$ body weight of a $20 \%$ solution of fluorescein sodium and 30 min later $25 \mu \mathrm{l}$ of $0.1 \%$ solution of PAF in phosphate buffered saline (PBS) was applied to the right eyes. The left eyes served as controls and received $25 \mu \mathrm{l}$ of PBS.

Thirty min after application of PAF or PBS tears were collected by washing the surface of the eye with $25 \mu \mathrm{l}$ of PBS, using a polypropylene micropipette, avoiding touching the eye. After three forced blinks the lavage fluid was collected and stored at $-20^{\circ} \mathrm{C}$ until use. Blood was collected by heart puncture of the animals, anticoagulated with heparin and centrifuged for separation of the plasma.

Albumin concentration in lavage fluid was determined using a radial immunodiffusion method in agar plates $(1.5 \%$, containing guinea pig albumin antiserum in 1:100 dilution. Various concentrations of guinea pig albumin were used as standard. Samples $(5 \mu \mathrm{l})$ were tested in appropriate dilutions.

Fluorescein was measured in lavage fluid and plasma by fluorophotometry, using a fluorophotometer (Fluorotron Master, Ocumetrics Inc., Mbuntain View, CA, USA). For measure- 
ment in lavage fluid $20 \mu \mathrm{l}$ was diluted in $0.5 \mathrm{ml}$ of PBS in a 5 mm-cuvette and plasma $20 \mu \mathrm{l}$ was diluted in $4 \mathrm{ml}$ of PBS in a $10 \mathrm{~mm}$-cuvette. Fluorescence was measured in the range 510 $600 \mathrm{~nm}$, using an excitation wavelength of $430-490 \mathrm{~nm}$.

PAF was purchased from Cayman (Ann Arbor, M, USA), guinea-pig albumin antiserum and guinea-pig albumin from Nordic (Tilburg, The Netherlands). Animals were housed and cared in accordance with rules and regulations of the European Community Board concerning the use of experimental animals (86/609/ CEE).

\section{Results}

Fig. 1 shows a significant correlation of the fluorescein concentration, expressed in percentage of the plasma concentration, and the albumin concentration in the lavage fluid of eyes, treated with PAF, in eight animals. The concentrations of fluorescein and albumin in lavage fluid of PBS treated eyes were below the detection limit of respectively $3 \mathrm{ng} / \mathrm{ml}$ and $15 \mu \mathrm{g} / \mathrm{ml}$. The measured concentrations of fluorescein in plasma varied from 11.2 to $25.0 \mu \mathrm{g} / \mathrm{ml}$ (mean $16.3 \pm 1.7$ ) and in lavage fluid from 3 to $257 \mathrm{ng} / \mathrm{ml}$ (mean $147.5 \pm 38$ ). Albumin concentrations varied from 0 to $376 \mu \mathrm{g} / \mathrm{ml}$ (mean $188 \pm 48$ ).

\section{Discussion}

The variation of the appearance of albumin in the lavage fluid of the eyes in response to local application of PAF is in correspondence with our observations, described earlier. ${ }^{1}$ The great variation in response may be explained by

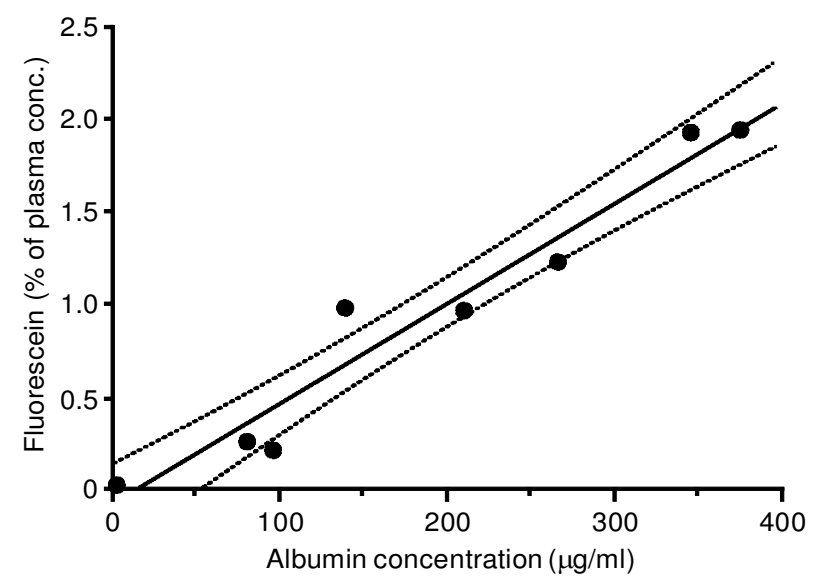

FIG. 1. Relationship between albumin and fluorescein in lavage fluid of eyes of guinea pigs, collected 30 min after treatment with $25 \mu \mathrm{l}$ of $0.1 \%$ PAF. Correlation coefficient $0.98(P<0.0001, n=8)$. variation in the penetration of the outer eye. The resorption depends on the ocular contact time of the eye drop, containing PAF, and on enzymatic hydrolysis of PAF to lyso-PAF by an acetylhydrolase, present in ocular tissue. ${ }^{4} \mathrm{Sev}-$ eral ocular tissues themselves, subsequent to inflammation, are able to produce $\mathrm{PAF}$ in ng quantities. 5

Albumin is not produced by the lacrimal gland of the guinea pig $^{6}$ and the appearance of albumin on the ocular surface is a result of the flow of plasma protein containing tissue fluid across the epithelium to the ocular surface under the influence of PAF. The lavage fluid from the surface of the eye at this stage contains a mixture of leaking plasma and lacrimal gland fluid from the lacrimal gland.

The amount of fluorescein leaking out of the blood vessels is dependent on the rapidly changing concentration of fluorescein in the blood. Therefore fluorescein concentrations are calculated as percentage of the plasma concentration. The same should apply for serum albumin, however the plasma concentration of about $45 \mathrm{~g} / 1$ is not likely to change in short-time experiments as carried out in this study. The greater part, more than $90 \%$ of fluorescein in blood is bound to protein and this explains the relationship in lavage fluid found for albumin and fluorescein. The determination of albumin in lavage fluid as a measure for conjunctival inflammation is a relatively simple method.

The Evans Blue method for measuring extravasation of plasma in inflamed conjunctival tissue is based on the same principle of comigration of dye with plasma proteins. However it is an invasive procedure where the animals have to be killed for isolation of the conjunctival tissue and extraction of extravasated dye. The concentration of Evans Blue in the tears is too low to be detectable by colorimetry compared with fluorescein, which can be measured fluorimetrically with a detection limit of $1 \mathrm{ng} / \mathrm{ml}$. Measurement of fluorescein in lavage fluid of the eyes is an alternative for Evans Blue with the advantage that it is not necessary to kill the animals.

\section{References}

1. Meijer F, van Delft JL, van Haeringen NJ. Platelet-activating factor: an inflammatory mediator in the acute phase of alle rgic conjunctivitis in a guinea-pig model. Mediators Inflam 1995; 4: 191 -195.

2. Abelson MB, Schaefer K. Conjunctivitis of allergic origin: immunologic mechanism and current approaches to therapy. Surv Opthalmol 1993; 38: $115-132$.

3. Hwang SB, Li CL, Lam MH, Shen TY. Characterization of cutaneous vascular permeability induced by platelet-activating factor in guinea pigs and rats and its inhibition by a plate let-activating factor antagonist. Lab Invest 1985; 52: 617-630. 
4. Bazan HEP, Tao Y, Hurst JS. Platelet-activating factor antagonists and ocular inflammation. J Ocul Pharm acol 1994; 10: 319-327.

5. Rosenbaum JT, Boney RS, Samples JR, Valone FH. Synthesis of platelet activating factor by ocular tissue from inflamed eyes. Arch Ophth almol 1991; 109: 410-413.

6. Thörig L, van Agtmaal EJ, Glasius E, Tan KL, van Haeringen NJ.
Comparison of tears and lacrimal gland fluid in the rabbit and guinea pig. Curr Eye Res 1985; 4: 913-920.

Received 15 May 1997;

accepted in revised form 12 June 1997 


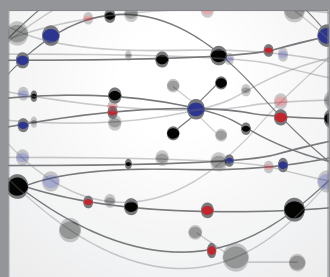

The Scientific World Journal
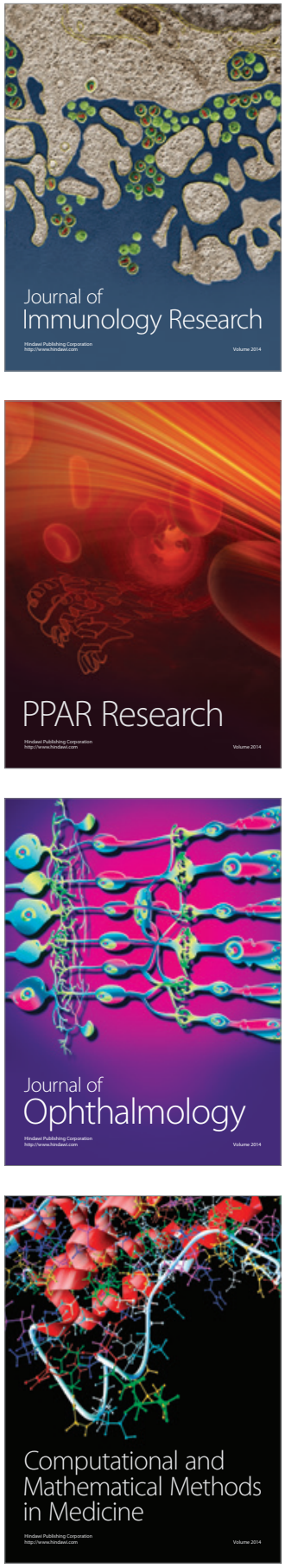

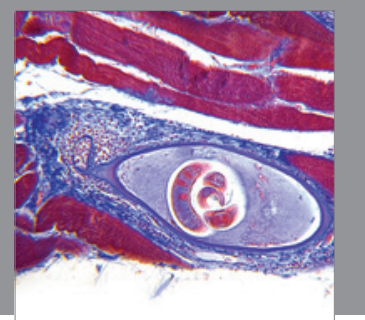

Gastroenterology

Research and Practice
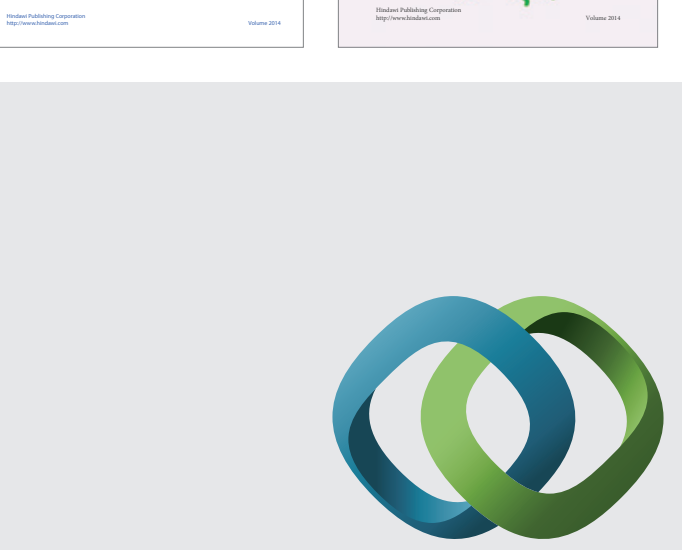

\section{Hindawi}

Submit your manuscripts at

http://www.hindawi.com
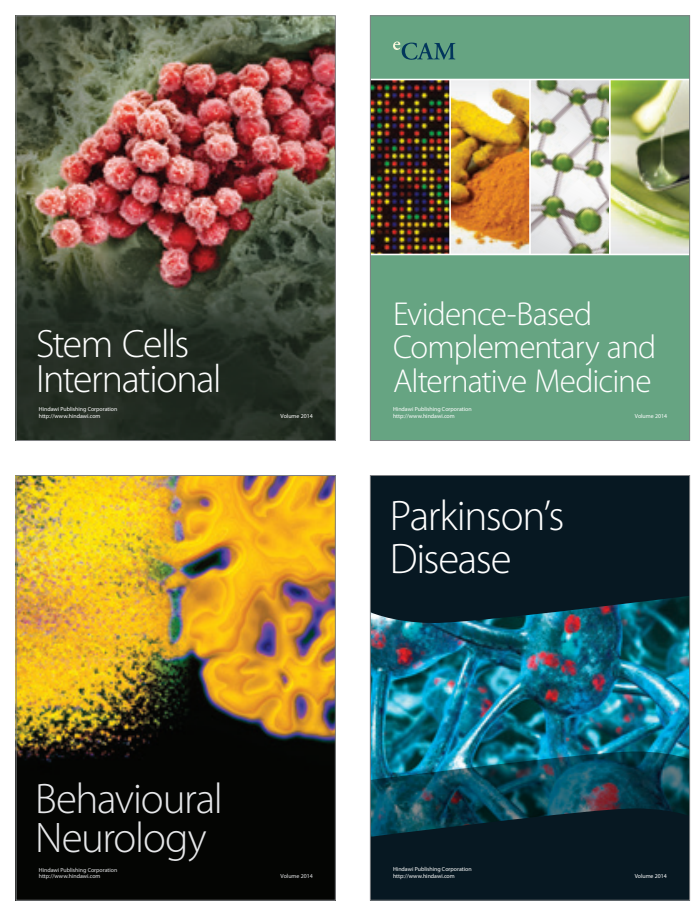

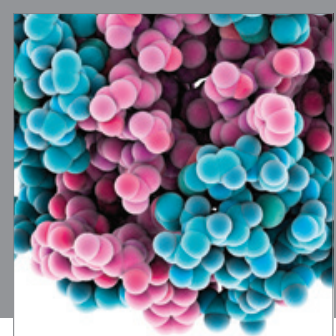

Journal of
Diabetes Research

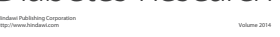

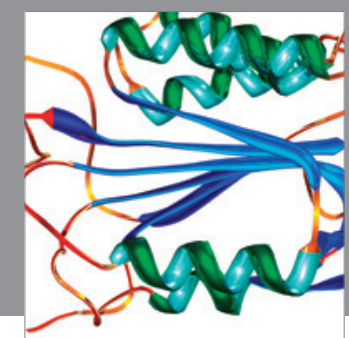

Disease Markers
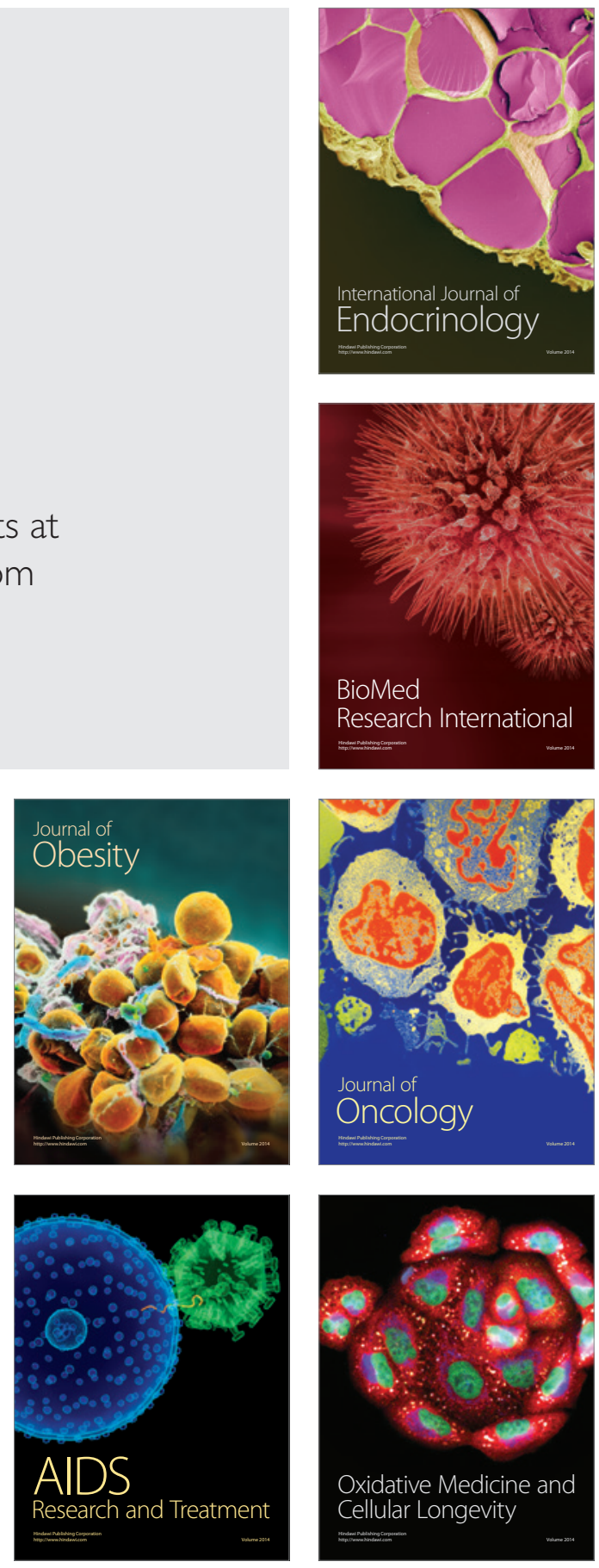